\title{
Iron isotope constraints on the genesis of giant Beiya Au-base metal deposits, Yunnan, southwest China
}

\author{
Wenyan $\mathrm{He}^{1 *}$, Yanlu Xing ${ }^{2}$, Yong-Sheng $\mathrm{He}^{1}$, Xue $\mathrm{Gao}^{1}$ \\ ${ }^{1}$ State Key Laboratory of Geological Processes and Mineral \\ Resources, China University of Geosciences, Beijing 100083, \\ China \\ ${ }^{2}$ School of Earth, Atmosphere and Environment, Monash \\ University, VIC3800, Australia
}

The Beiya Au-base metal deposit in southwest China is characterised by its huge amount of iron associated with gold mineralization. The formation of the Beiya deposit is generally thought to be related to Tertiary potassic intrusion, as porphyry- and skarn-type mineralization are the two most important types of mineralization in the region. However, it is still not well understood on the source of iron and gold, as well as other metals, given the absence of direct evidence to constrain the source and mobilization mechanism of metals. In this study, with the help of multi-collector inductivelycoupled plasma mass spectroscopy (MC-ICP-MS) was used for high-precision $\mathrm{Fe}$ isotope analyses on Fe-bearing minerals including magnetite, pyrite and chalcopyrite from the orebody, and on major igneous rocks exposed in the area, including monzogranite porphyry (MGP), mafic microgranular enclave (MME), lamprophyre and basalt. Magnetites have a wide range of $\delta 56 \mathrm{Fe}$ varying from $0.15 \pm$ $0.03 \%$ to $0.64 \pm 0.03 \%$, which indicate isotopic fractionation during the formation of ore bodies at different stages. MGPs have $\delta 56 \mathrm{Fe}$ varying from $0.19 \pm 0.03 \%$ to $0.48 \pm 0.02 \%$. MMEs have the heaviest $\mathrm{Fe}$ isotopic composition with $\delta 56 \mathrm{Fe}$ ranging from $0.35 \pm 0.03 \%$ to 0.88 $\pm 0.03 \%$. Both MPGs and MMEs show a significant overlap with magnetites in terms of $\mathrm{Fe}$ isotopic compositions. A negative correlation for $856 \mathrm{Fe}$ and $\mathrm{TFe} 2 \mathrm{O} 3$ is found for these two types of rocks, which provides evidence on the leaching of iron by hydrothermal fluids that mobilize light $\mathrm{Fe}$ and leave behind isotopically heavy $\mathrm{Fe}$ in the remaining source rock. A merge of iron from both MGPs and MMEs is proposed to be the source of $\mathrm{Fe}$ in magnetites. Regional basalt has a $856 \mathrm{Fe}$ value of $0 \pm 0.03 \%$, similar to the values for global basalts, suggesting a negligible contribution to the formation of iron ores. For lamprophyres, their $\delta 56 \mathrm{Fe}$ values are located in a relatively small changing range with no significant correlation to their whole rock iron content. Therefore, we infer that magmas parental to the MGPs and MMEs may be the main sources providing iron to form the Beiya deposit, and post-magmatism hydrothermal activities play a major role on metal extraction and transporting. 